\title{
Extant Design: designing things as they are
}

\author{
S. Walker \\ Faculty of Environmental Design, University of Calgary, Canada
}

\begin{abstract}
A brief overview of two quite different but interrelated ways of addressing sustainability in relation to product design, namely "incremental improvement through design" and "more fundamental considerations of sustainability and product design" is followed by a design exploration that focuses on the second, while also incorporating aspects of the first. The basis of the exploration is described, and supplemented with tangible examples that illustrate the ideas. The focus of the discussion and the design work is on the still-useful objects that are so readily discarded and replaced because they are no longer regarded as useful, or for aesthetic reasons, or because minor technical advancements render these older objects less desirable. The three design explorations included here attempt to offer ways of re-valuing older products, thereby increasing their useful life and, in the process, making some contribution to mitigating the need for and effects of replacement products.
\end{abstract}

Keywords: sustainability, product design, material culture, novelty, consumerism, moderation.

\section{Introduction}

A contemporary challenge for design is to re-imagine and re-interpret some of our most fundamental notions of material culture. This is important for two reasons. Firstly, it is critical that we begin addressing sustainable issues in a much more substantial manner than has been evident to date. Secondly, if design is to contribute to human culture in a more meaningful way then it has to move beyond the often shallow, style-based notions of product design that have become so prevalent over the last 50 years.

Here, a discussion of approaches to sustainable design that might be termed 'incremental product improvement' models, are contrasted with approaches that 
take a much more radical approach to material culture. In addition, the latter forms the basis for a design exploration that is described and illustrated.

\section{Design and sustainability}

The continuous production of new products, with new aesthetic expressions, and accompanied by relentless marketing campaigns, is intended to create a sense of dissatisfaction with one's possessions, leading to the replacement of older products with new, Chapman [1]. Even though the older product may still be perfectly serviceable, it becomes prematurely obsolete because, over time, it grows shabby and outdated in its appearance and because fresh, new styles are made available to us. While the production and consumption of new products satisfies economic objectives, spurs business growth and gives temporary pleasure to the user, there are also a host of well documented problems associated with this conception of material culture that render it fundamentally unsustainable - sustainability, in its basic form, being attendant to the triple bottom-line of environment, ethics and economics, Elkington [2].

Ironically 'sustainable product design', as the name implies, is also often pursued by designing new products that in some manner address sustainable principles - perhaps through the use of more benign materials, or by employing up-to-date, cleaner technologies. In recent years, a host of incremental strategies have been developed to improve the environmental performance and, in some cases, the social ramifications associated with current manufacturing. These include programs such as The Natural Step, Robert [3], Cradle-to-Cradle design, McDonough, W. and M. Braungart [4], Product Life Cycle Assessment, Pré [5], and Factor 10 [6]. All of these offer pragmatic solutions for modifying current practices in order to reduce the negative impacts of product design and production. They are important models for implementing improvements in the existing system, but they do little to challenge the basis of that system. Moreover, these 'incremental product improvement' models result in more objects being manufactured by using more resources and more energy. So this interpretation of sustainable product design, while it may contribute to the improvement of products over time, has some inherent problems associated with it.

These approaches can be seen, in varying degrees, as part of the problem rather than the solution because they bolster, rather than challenge, the current consumerist model of a totally commodified material culture - a model that is manifestly destructive. Modern marketing, of which product design has always been a part, Sparke [7], is based on creating dissatisfaction with what we have, Chapman [8]. It fosters discontentment and tells us, unremittingly, to want more, that we deserve more. It promotes consumerism and desire for the novel, and gives rise to disquiet and yearnings that can never be sated. When we fall victim to this, we can never find happiness; happiness, in many traditions, being synonymous with the notion of human satisfaction, e.g. McCabe [9]. Thus, it could be said that our contemporary market system sells, more than anything else, discontent and unhappiness. 
Incremental improvement models do not address this problem in any significant way. They may ameliorate certain negative effects but they do little to find a way out of a production system that is evidently environmentally, socioculturally and personally damaging.

It is important to acknowledge that there are many new developments in science and technology that do make genuine and valuable contributions. However, the concern in this present discussion is with the plethora of products that are continually restyled, perhaps with the addition of some relatively trivial updates and features to grab our attention. In the context of sustainability, these products represent an immoderate use of resources, they help generate waste and pollution, and, through marketing, they help create dissatisfaction.

\section{A changing role for design}

If, as I suggested above, the creation of new products is, indeed, part of the problem rather than the solution, then what is left for the designer? Does the designer still have a contribution to make? On the face of it, and within the conventional parameters of product design, it would seem that the answer would be no, or at most, relatively little. However, if we are prepared to broaden our horizons a little, and think of designers not simply as the creators of novel products, but as creative individuals who think about and contribute to the nature, meaning and design of material culture, then they will have an important role to play in re-conceptualizing and redefining our notions of functional objects. Potentially, the creative abilities of the designer can be critical in a world where excessive consumption and waste are leading us down a self-destructive path. In developing this role, design within academia can make a significant and reflective contribution, removed as it is from the pressures of the business environment. As Fuad-Luke [10] has suggested, to develop new roles for contemporary design it is important to separate it, at least temporarily, from economic considerations.

If designers are to address the challenge of sustainability in a more substantive manner, they must question the ways in which they design, the assumptions they make, and the products of design. Some academics and designers are already doing this - by developing new approaches and strategies, and new understandings of the contribution and role of the designer. There are a number of directions that can be seen as much more fundamental explorations of our understanding of material culture, compared to the incremental approaches discussed earlier. For example, Chapman [1] has looked at the psychology of consumerism and considered ways of creating more meaningful relationships with objects; Fuad-Luke [10] has explored the notion of 'slow design', which focuses on personal, socio-cultural and environmental well-being; and Manzini and Jégou, [11] have developed strategies for 'enabling solutions' at the local level, which allow people to become more involved and self-determining in the development of their products and services. Compared to the incremental improvement models, these approaches are more demanding, more difficult to 
envision, and less comfortable because they challenge our contemporary conventions and our basic assumptions about the nature of products.

Integral to many of these approaches is the use of design as a method for illustrating alternative notions of functional objects. Designers and designcentred academics can attempt to re-imagine the nature of objects through the practice of design itself. Drawing on the plethora of material that is available on the relationship between material culture, consumerism, and environmental and social effects, designers can explore new design methods and develop alternative approaches to the definition of 'functional object'. There are a number of examples of such designers, including the Droog group based in the Netherlands, Ramakers (ed.) [12], the Campana brothers in Brazil [13], and the Boyms in the United States [14]. All these, in their own distinctive ways, challenge current norms of mass-produced products - conceptually, aesthetically and philosophically.

\section{Extant design}

The exploration in this paper describes and illustrates, through examples, a direction that leans more to these alternative approaches. In other words, a consideration of our relationship with objects is followed by an engagement in the process of design in order to translate these considerations into tangible, functional objects.

More specifically, it explores an alternative to the novelty-based, voguish approaches to design that are so dominant today, and which tend to maintain design as an arm of advertising to spur consumerism, Woodham [15]. This influential aspect of the design profession may contribute to the continuous growth model of modern economics but, in terms of sustainability, it creates a host of problems. And, as was mentioned earlier, the avid consumerism stimulated by corporate agendas does little to enhance our sense of fulfilment or personal happiness, DeAngelis [16].

Another way of thinking about design, and the products of design, can be based on acceptance of what is, rather than continuing the convention of designing the new, the novel and short-lived. The first of the three r's associated with environmental responsibility is reduce, which can be applied to consumerism as much as to the use of materials and energy. A reduction in consumerism is logically related to the second of the three r's, i.e. re-use. If we reduce consumerism, then we have to re-use what we already have. Reducing and re-using are both more important and should be given higher priority than the third ' $r$ ' of recycling, yet it is recycling that has received far more attention. This is because is can be more easily accommodated within our current design and production system. Reduction and re-use require a more drastic reassessment of the nature and norms of contemporary material culture.

The design examples included here also take into consideration a variety of other sustainable principles such as product longevity, localization, and selfdetermination, and they acknowledge the social and environmental costs of 
manufacturing industry, European Commission [17]; Scott [18]. Clearly, these various elements of sustainable design are interlinked and they raise a number of questions about the nature and meaning of design, the place of design, and our understanding of what it means to be a designer in a world straining under the pressures of consumerism.

The objects presented here are examples of 'academic design', as distinct from commercial design. They represent an exploration from within the discipline of design itself and are an attempt to articulate ideas about objects. The result is a number of artefacts, each of which includes products that had been discarded. In all cases, new technologies have been added, to enable the still-functional aspects of older products to find renewed usefulness - thus the designs integrate old objects with new, and link contemporary mass-production with the benefits of reduction and re-use. Furthermore, the artefacts are created in ways that are suited to the diversity and restrictions of 'locale'. Thus, they deal with issues of aesthetic obsolescence, moderation, waste, localization and self-reliance.

These design explorations raise questions about our understandings of products in the context of sustainability. Design is used as a means to re-present familiar and/or unwanted products so they can be re-used and seen anew. This contributes to the pressing debate about sustainability and manufactured objects through an exploration of material culture that stands outside current norms of newness and novelty. The intention is to find a place for design that is more meaningful, more lasting and which can contribute to a culture of moderation and acceptance.

\section{Explorations in Extant Design}

The approach taken in this present series of works will, hopefully, begin to illustrate aspects of the changing role of product designers who wish to address sustainability. The focus here is on what we might term 'the lost products of contemporary society'. These are unwanted objects and older products that, for aesthetic reasons, are no longer regarded as fashionable, but which are not yet old enough to have value as retro or antique objects. These are the products that are so readily cast aside and replaced.

Using the discarded, finding a place for the rejected, and reusing the broken are ways of treasuring, honouring and respecting not only the resources of the earth, but also the time, thought and ingenuity that have already gone into these objects. Exploring how to use them again, beyond their first use, is a way of further justifying and valuing their presence in the world. It may seem unfashionable to say so, but it is a form of appreciation and a way of respecting, even sanctifying, the world, its people and its resources. More than this, representing older, existing products in a new light can allow us to accept them as they are, and despite their unfashionable styling and their wear and tear, be content with them, to see them as enough.

There are admirable models for these types of explorations, from the readymades of Duchamp in the early years of the twentieth century, Ades et al [19], to 
the more recent work of Rauschenberg in which found objects are incorporated into sculptural pieces. Rauschenberg's work in particular, while not addressing utility, nevertheless salvages and resurrects the discarded, the abused and the lowly objects that are so unconscionably abandoned in today's affluent societies Rose [20].

The first artefact in this present set of design exercises, 'Soundbox' (figure 1), was conceived as a more conventional 'product'. It combines a new MP3 player with recovered computer loudspeakers with an integral amplifier. These objects have been assembled in a very rudimentary manner, by placing them in a re-used cardboard box. While aesthetically crude, the exercise was an attempt to re-use products in a way that could be readily achieved at the local level without special knowledge or tools.

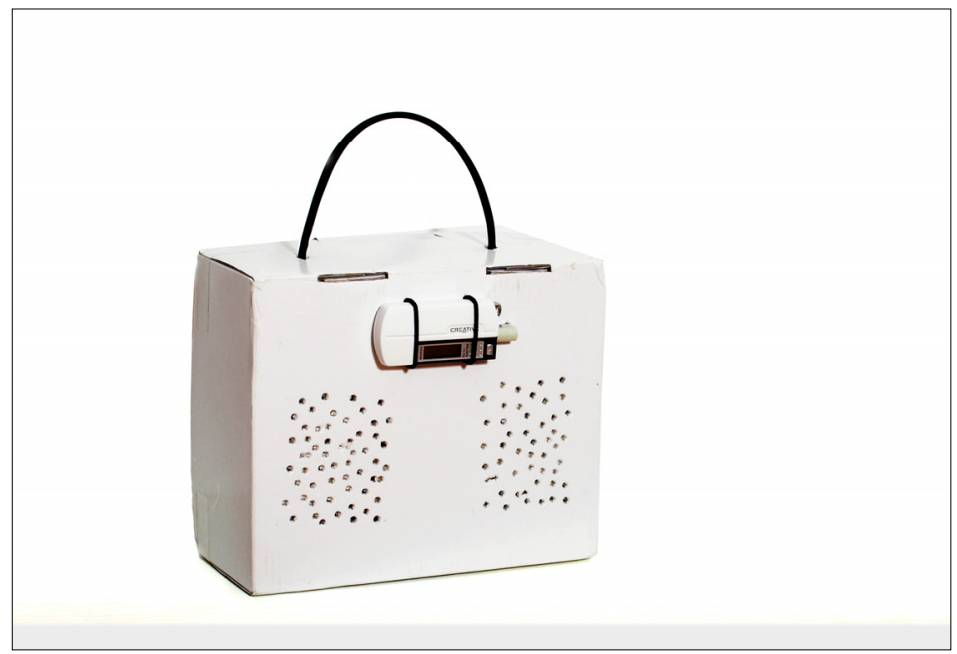

Figure 1: Soundbox. A new personal MP3 player combined with re-used, unfashionable computer speakers with integral amplifier assembled in a rudimentary manner in a cardboard box.

While this design achieves this objective, it was recognized that, aesthetically, a different approach was needed. In the later explorations, 'Lamplight' (figure 2) and 'Replay' (figure 3) the re-used objects have been separated from their surroundings and used as components within larger compositions.

In these cases, the objects are mounted on specially built, neutral armatures to create 'functional arrangements'. In a sense, this places them on a pedestal, and re-contextualises them so that they may be seen from a somewhat different perspective. The approach is one in which the individual, re-used objects become mere elements within a greater whole. Thus, the emphasis is shifted - the focus is no longer on an out-of-date, imperfect old product but, instead, is on the entire composition. In addition, the re-used objects are no longer hidden, as they were in 'Soundbox', nor are they disguised to hide their previous use or their 
unfashionable styling. Within the larger compositions, they 'work' as they are and for what they are. Thus, they attain a renewed dignity and a new value by becoming integral components of a contemporary composition.

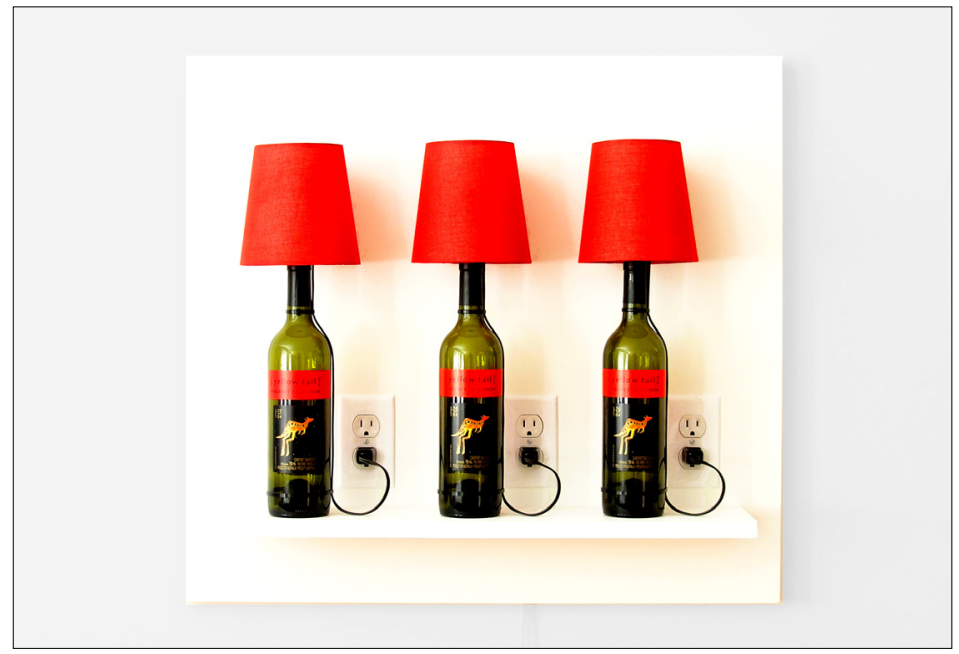

Figure 2: Lamplight. Re-used bottles, new lampshades, low-energy bulbs on a white armature with shelf.

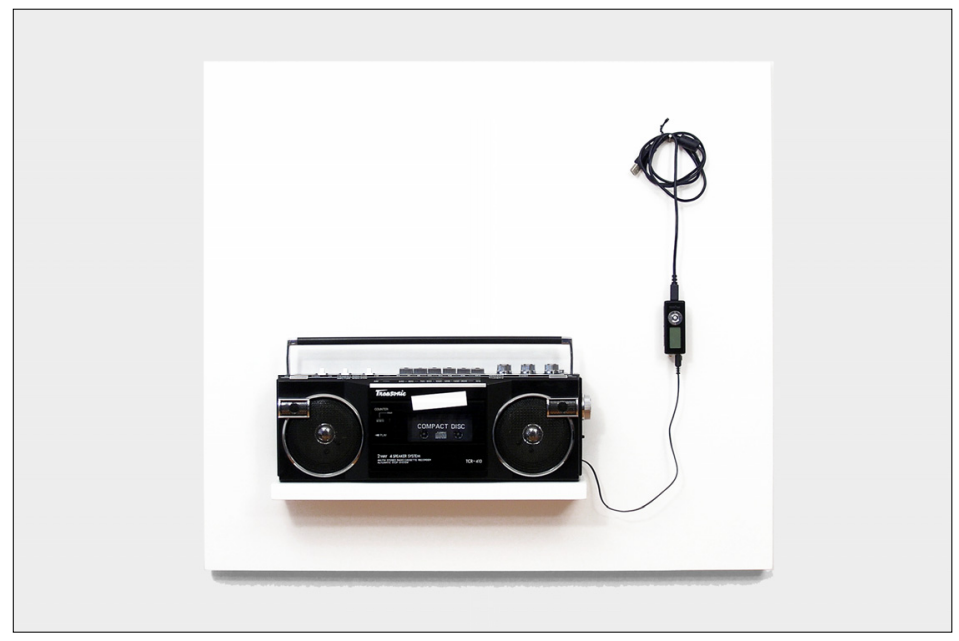

Figure 3: $\quad$ Replay. New personal MP3 player, re-used, 1980s cassette stereo on a white armature with shelf.

These explorations are intended to contribute to the development of a new role for design - a role that is more attuned to the needs of people, society and the environment. These examples are not presented as an end point, but simply 
as small steps along a road of rediscovering a new, perhaps more valid and more profound role for design that stands outside the destructive system of unfettered production and waste that is so prevalent today. Moreover, this approach implies a rather different design process than is common today in industrial design; the process here being more akin to collage or assemblage, rather than the ex nihilo methods of contemporary practice.

It is pertinent to point out that this approach does not ignore technological development or innovation, instead it attempts to use it where it seems appropriate to do so. For example, in 'Replay (figure 3), an old stereo cassette player has been slightly modified to allow the use of MP3 technology. In this way the benefits of the MP3, which dispenses with the need for cassette or compact disc production, with their attendant packaging and distribution, are combined with the existing and still serviceable amplifier and speakers of the older product. This is a more moderate solution than discarding the old product and replacing it with a new speaker system designed to go with an MP3 player. The older product is adapted, re-used and, through re-presentation, re-valued.

This example differs in intention from the explorations carried out by Droog designers Wolf, Bader and Oschatz. In their "Bootleg Objects" series, classic designs from the past were updated to use MP3 technology. The chosen products included Dieter Rams' 1962 Braun Audio, a 1973 Bang \& Olufsen system, and the Technics SP1210 record deck from 1980, Williams [21]. All these products are now recognised for their design excellence and therefore already have value; these products were chosen precisely because they are regarded as classics. Hence, they are not typical of the kind of products that end up in landfill. They have passed the transitional period that renders products undesirable and have reached an age and a rarity that makes them, once again, sought after items.

By contrast, the products selected for use in the examples included here have no such design cachet. This is best illustrated in the cassette player that forms part of the MP3 Speaker composition, 'Replay' (figure 3). The cassette player was selected precisely because it was no longer wanted, it was no longer regarded as aesthetically pleasing or fashionable, and it had no 'retro-chic'. The functional composition in which it features is an attempt to:

- Accept objects as they are - with their faded, unfashionable aesthetic and their scars of use.

- Value objects as they are - for the benefits they still offer.

- Respect objects as they are because in doing so we show respect for the thought, ingenuity, time and effort that have gone into their design. We also show respect for the resources and energy that have already been used in their production.

- Moderate our acquisitiveness - by re-representing and revaluing what we already have, rather than simply discarding and replacing older objects with new products.

- Slow the culture of distraction that acquisitiveness engenders. A distracted culture, ipso facto, cannot be self-reflective and this, in turn, tends to reinforce the present model of consumerism. 
Rather than describing these compositions in more detail, it is perhaps better to allow them to speak for themselves. The language of design is not words, it is not arguments and criteria. It is simply design itself. Words can take us some of the way but the artefacts themselves have to do the rest.

"Looking is a marvellous thing of which we know but little. Through it we are turned absolutely towards the outside, but when we are most of all so, things happen in us that have waited longingly to be observed; and while they reach completion in us... their significance grows up in the object outside." Rainer Maria Rilke, 1907 [22]

\section{References}

[1] Chapman, J., Emotionally Durable Design - Objects, Experience, Empathy, Earthscan, London, p.16, 2005.

[2] Elkington, J., Cannibals with Forks: The Triple Bottom Line of $21^{\text {st }}$ Century Business, New Society Publishers, Gabriola Island, BC, Canada, 1998.

[3] Robert, K. H., The Natural Step Story - Seeding a Quiet Revolution, New Society Publishers, Gabriola Island, BC, Canada, 2002.

[4] McDonough, W. \& Braungart, M., Cradle to Cradle - Remaking the Way We Make Things, Douglas \& McIntyre, Vancouver, BC, Canada, 2001.

[5] Pré, life cycle tools to improve environmental performance, Pré Consultants, Netherlands, http://www.pre.nl/, accessed November 28 2005.

[6] Factor 10 - an introduction, Factor 10 Institute, Canoules, France, http://www.factor10-institute.org/, accessed November 282005.

[7] Sparke, P., An Introduction to Design and Culture in the Twentieth Century, Allen \& Unwin, London, pp. 94-98, 1986.

[8] Chapman, J., Emotionally Durable Design, Earthscan, London, p.39, 2005.

[9] McCabe, H., The Good Life, Continuum, London, 2005.

[10] Fuad-Luke, A., SLOW - Slow theory - a paradigm for living sustainably? 2004, accessed at: www.slowdesign.org, accessed November $23^{\text {rd }} 2005$.

[11] Manzini, E. \& Jégou, F., Sustainable Everyday - Scenarios of Everyday Life, Edizioni Ambiente, Milan, 2003, and Manzini, E. \& Jégou, F., Album - A Catalogue of Promising Solutions, Edizioni Ambiente, Milan, 2003.

[12] Ramakers, R., (ed.), Simply Droog - 10+1 years of creating innovation and discussion, Droog Publishing, Amsterdam, 2004.

[13] Campana, F. \& H., Interview with Fernando + Humberto Campana, 2005, accessed at: http://www.designboom.com/eng/interview/campana.html, accessed November 232005.

[14] Boym, C \& L. L., Curious Boym - Design Works, Princeton Architectural Press, New York, 2002. 
[15] Woodham, J. M., Twentieth-Century Design, Oxford University Press, Oxford, pp. 145, 227-228, 1997.

[16] DeAngelis, T., Consumerism and its discontents, Monitor on Psychology, American Psychological Association, Vol. 35, No. 6 June 2004, http://www.apa.org/monitor/jun04/discontents.html, accessed Nov. 25 2005.

[17] European Commission (2004) EU policy-making - counting the hidden costs, European Commission Environment Research document, August 16 2004, accessed at: http://europa.eu.int/comm/research/environment/ newsanddoc/article_1444_en.htm, November 252005.

[18] Scott, R. (2003) The high price of 'free' trade, Economic Policy Institute, Washington D.C., EPI Briefing Paper \#147, November 17, 2003, accessed at: http://www.epinet.org/content.cfm/briefingpapers_bp147, Nov. 25 2005.

[19] Ades, D., N. Cox \& Hopkins, D., Marcel Duchamp, 'World of Art' series, Thames \& Hudson, London, p. 146, 1999.

[20] Rose, B., Rauschenberg - On and Off the Wall, in "Rauschenberg - On and Off the Wall - Works from the 80's and 90's", Musée d'Art moderne et d'Art contemporain, Nice, France, pp. 47-73, 2005.

[21] Williams. G., Use it again, in Ramakers, R., (ed.), Simply Droog, Droog Publ., Amsterdam, pp. 25-34, 2004.

[22] Rilke, R. M., Looking is a Marvellous Thing - from Rainer Maria Rilke's letters to his wife Clara, on looking at Cézanne's pictures in the Salon D’Automne, Paris, October 1907, Hastings Arts Press, Hastings, UK, 1992. 